\title{
The Concept of Terms Related to Democracy in Euripides' Suppliant Women ${ }^{1}$
}

Farid H El-ANWAR

Ain Shams university

This study focuses on the words that refer to democracy in the play, Suppliant Women, written by the tragic poet Euripides, who lived in Athens at the fifth century B.C - the period of transition from dictatorship to democracy. ${ }^{2}$ And so it was natural that this period had an influence on his way of handling his plays to introduce the concept of democracy and its positive and negative aspects. ${ }^{3}$ Euripides uses terms remarkably to highlight the cooperative moral values, associated with democracy, such as selfcontrol and prudence, wisdom and justice, which help the democratic system to achieve its objectives.

The Suppliant Women aims at praising the city of Athens for its method of applying the principles of democracy and estimating the value of youth as a political force of the democratic system. ${ }^{4}$ Although the Suppliant Women introduces a simple subject which is "burial as a right for the dead", Euripides makes a good use of this event to show his perspective on the democratic system through a debate between the Messenger of Thebes' king, who represents the dictatorial regime and Theseus, the governor of Athens, who represents the democratic system. ${ }^{5}$ On one hand, Theseus shows us, in this debate, that the city of Athens has the best system of government which is the democratic system. ${ }^{6}$ On the other hand, the messenger of Thebes criticizes the democratic system for giving opportunity to demagogues to prefer their personal benefit at expense of the public good of the state.

Therefore, this research focuses on the positive and negative impacts of a democratic system, through analysis of some Greek terms which refer

Classical Papers, vol. xi , 2012 


\section{The Concept of Terms Related to Democracy in Euripides' Suppliant Women}

to the principles of democracy, and also introduces the characteristics that must be met in the found in the leader or demagogues in the democratic system. And surely, this research illustrates the dramatic function of these terms during the events of the play.

\section{The Positive Aspects of Democratic System}

Firstly, the most important advantages of the democratic system are

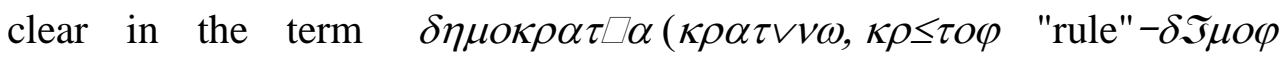
"people"), which means that the people govern themselves, and this is illustrated by various terms and expressions which support this meaning. When the Messenger of dictatorial Thebes asked, in his first appearance,

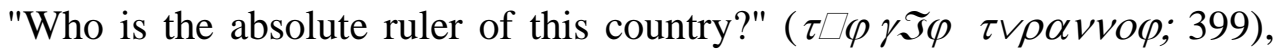
Theseus, the king of Athens Democracy, answered, "You made a mistake in your speech" ( $\pi \rho(\tau o v \mu \square v / \rho \xi \omega \tau o \diamond \lambda \Theta \gamma o v \quad \psi \varepsilon v \delta(\varphi 403)$, "there is no

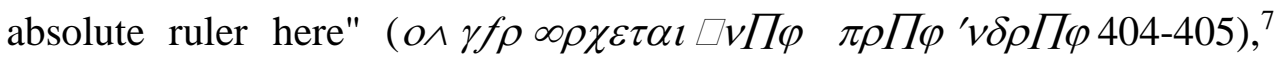
"the public govern" $\left(\delta \mathfrak{I} \mu \circ \varphi \delta{ }^{\prime}{ }^{\prime} v \leq \sigma \sigma \varepsilon \imath\right.$ 406). ${ }^{8}$

Theseus' refusal to be addressed as a $\tau \vee \rho \alpha \nu v o \varphi$ injects anachronistic modern reverberations and draws further attention to his own singular position among the Athenians. ${ }^{9}$ And when the Apostle of Thebes asks how the people can govern the city ( $\delta \Im \mu o \varphi \varepsilon \wedge \theta \vee v \varepsilon \imath v \pi \AA \lambda \iota \nu 418)$, and they are not capable of good judgment $\left(\mu-\delta \iota \rho \rho \theta \varepsilon v \omega v \lambda ® \gamma o v \varphi \nabla \rho \theta\left(\varphi \delta v v \alpha \imath \tau^{\prime} 417\right)\right.$, Theseus answers that the people of Athens are in charge of the land $(\delta \mathfrak{I} \mu \circ \varphi \varepsilon \wedge \theta v \nu \tau-\varphi$ $\chi \theta o v \Pi \varphi 422)$, he applies the equality in the city $(\square \sigma \alpha \square \tau \varepsilon \rho o v \pi 囚 \lambda \varepsilon \imath 441)$, and so the young men find the opportunity to ascend political offices $\left(\neg \pi \sigma \oslash \sigma \imath v^{\prime} \sigma \tau \sigma \square \varphi \ldots \delta \varepsilon \tau \alpha \imath v \varepsilon \alpha v \square \alpha \imath \varphi 443\right)$. But in the dictatorial regime, the Tyrant, worrying about his power ( $\delta \varepsilon \delta o \imath \kappa<\varphi \tau \mathfrak{I} \varphi \tau \cup \rho \alpha \nu v \square \delta o \varphi \pi \square \rho \imath 446$ ), kills the best youth among the citizens $\quad\left(\tau o \Uparrow \varphi^{\prime} \rho \square \sigma \tau o v \varphi \kappa \tau \varepsilon \square v \varepsilon \imath\right.$ 445-446). ${ }^{10}$ Consequently Euripides uses Theseus as a character to make clear the political implications of the 


\section{Farid El-ANWAR}

theme of youth and their meaning for the play as a whole. Youth is emphasized throughout the play, because they are a vital political force, a force whose behavior shows the success or failure of the government. ${ }^{11}$

And the king of Athens confirms that democracy allows the people to make the important decisions of the country such as the decision of war it is the right of the people only to reach this resolution. When Aithra, the king's mother, asks her son to help the suppliants to bury their children, even if the need arises for the war (325-331), Theseus agrees, but declares that it is better to consult the people, the master of the decision

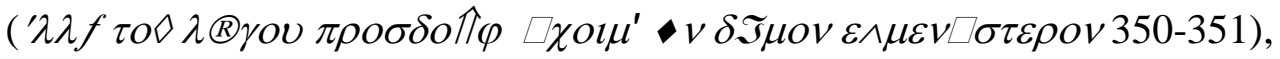
and hold the supreme authority ( $\left.\kappa \alpha \tau \square \sigma \tau \eta \sigma^{\prime} \alpha \wedge \tau \Pi \backslash v \square \varphi \mu o v \alpha \rho \chi \square \alpha \nu 352\right)$, as the city enjoys freedom ( $\square \lambda \varepsilon v \theta \varepsilon \rho(\sigma \alpha \varphi \tau \approx v \pi \AA \lambda \iota v 353$, see also $\square \lambda \varepsilon v \theta \square \rho \alpha \pi 囚 \lambda \iota \varphi 405,477)$, and everybody has equal rights of vote without discrimination $(\square \sigma \Re \psi \eta \phi o v 353) .{ }^{12}$

The term $v \Re \mu o \varphi$ is one of the fundamental terms that reflect law which guarantees achievement of the democratic system's objectives such as equality, justice and freedom. This term has come in a variety expressions that emphasize its importance for democracy. When Theseus compares the negative aspects of dictatorial Thebes with the positives of democratic Athens, he introduces laws as an example of democracy's principles. In the dictatorial system, the people are ruled by the tyrant

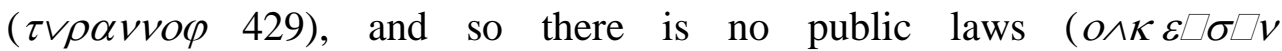
$v \ll \mu o \imath$ Kolvo $\square 430-431)^{13}$, the tyrant has all laws in his hands $(\kappa \rho \alpha \tau \varepsilon \square$ $\left.\delta^{\prime} \varepsilon \square \varphi \tau \Pi \nu \nu R \mu o v \kappa \varepsilon \kappa \tau \eta \mu \square \nu O \varphi 431\right)$, and therefore there is no equality

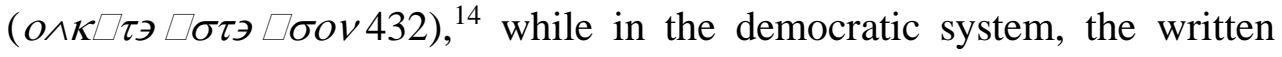
laws ( $\gamma \varepsilon \gamma \rho \alpha \mu \mu \square v \omega v \delta \square \tau(v \nu \Re \mu \omega v 433)$ guarantee, for all classes of people, equality and justice (' $\sigma \theta \varepsilon \nu \longrightarrow \varphi \angle \pi \lambda \sigma \vee \sigma l \Re \varphi \tau \varepsilon \tau-v \quad \delta \square \kappa \eta v$ $\square \sigma \eta v \square \chi \varepsilon \imath$ 433-434). ${ }^{15}$

There are other expressions urging to respect these laws in the light of the democratic system; For example Aithra encourages her son, the king, to help the suppliants as he must abide by the strict implementation of laws 


\section{The Concept of Terms Related to Democracy in Euripides' Suppliant Women}

$(v \circledast \mu o v \varphi \sigma(\iota \zeta \eta \imath \kappa \alpha \lambda l \varphi 313)$. This is the Charter which links the countries ( $\tau \Pi \gamma \leq \rho \tau o l \sigma v v \square \chi o v \quad{ }^{\prime} v \theta \rho(\pi \omega v \pi \AA \lambda \varepsilon l \varphi \quad 312),{ }^{16}$ and the chorus of suppliants asks the city of Athens to bury their sons, so as not to desecrate the canons of human beings ( $\nu \circledast \mu o v \varphi \beta \rho o \tau(v \mu-\mu l \alpha \square v \varepsilon \imath v 378)$.

The theme of the play throws light also on the law of citizen's right to be buried after death by various terms, as it is a religious law in the democratic system which is considered a civil law for humans. ${ }^{17}$ Theseus reassures both the mothers of the dead and the commander Adrastos that he will ask Creon, the king of Thebes, to bury the dead ( $\theta \leq \psi \alpha \iota \delta \imath \kappa \alpha \iota(526)$, because the law of Greece supports the religious principle of burying the dead ( $\tau \Pi v \Pi \alpha v \varepsilon \lambda \lambda \approx v \omega v \nu \circledast \mu o v \sigma(\iota \zeta \omega v 526-527,670-672)$, and this law should prevail ( $\wedge v \tau \varepsilon \theta \mathfrak{I}_{l} v \circledast \mu о \varphi 541$ ); for the lack of application of this law, will harm Argos and all Greece (537-538). ${ }^{18}$

The term $\nu \circledast \mu o \varphi$ was mentioned repeatedly with the law of burialright, to assure us that the worldly laws accord with the religious laws, in the light of democratic system. When Theseus takes the decision to bury the dead ( $\aleph^{\prime} \delta \Im \lambda \alpha \tau^{\prime} v \theta \square v \delta^{\prime} \cdot \varepsilon \square \mu \imath \kappa \alpha \square \theta \leq \psi \omega \beta \square \alpha \iota 560$ ), he explains that by saying, "So as not to say in Greece that the ancient heavenly laws have been destroyed" ( $\left.v \circledast \mu \circ \varphi \pi \alpha \lambda \alpha \imath \prod \varphi \delta \alpha \imath \mu \circledR v \omega v \delta l \varepsilon \phi \theta \leq \rho \eta 563\right){ }^{19}$

Theseus has declared that his belief, in an optimistic view of the world, based on law and order, ${ }^{20}$ and democracy is the best embodiment of that law and order within the state; therefore he goes to war with tyrannical Thebes to preserve, in the international sphere, those laws without which civilization and the rational ordering of society are impossible. ${ }^{21}$

The term $\delta \square \kappa \eta$ is introduced in this play in a variety of expressions to illustrate the importance of justice for the stability of society under the democratic system and also its importance for avoiding war and achieving peace in the world. Aithra is not worried about her son in the war, for he has justice on his side, and so he is not accompanied by fear $(o \Leftarrow \tau \varepsilon \tau \alpha \rho \beta$ ( $\sigma \hat{\Uparrow} \nu \delta \sqcap \kappa \eta \imath 328)$. The chorus of suppliants praises the city of Athens that reveres justice and hates falsehood $(\sigma \square \beta \varepsilon \imath \varphi \delta \square \kappa \alpha \nu$, 


\section{Farid El-ANWAR}

' $\delta \imath \kappa \square \alpha \imath v \square \mu \varepsilon \imath \varphi 379)$, because the justice ensures that there is no violation of the human beings' laws ( $₫ \mu$ ov $\varphi \quad \beta \rho o \tau(v \mu-\mu \imath \alpha \square v \varepsilon \imath v 378)$, and always protects the weak from injustice of the strong $(\delta v \sigma \tau v \chi \mathfrak{I} \tau \ni$ ' $\varepsilon$ $\pi \leq v \tau \alpha \bullet v \eta \imath$ 380). ${ }^{22}$

The law plays an important role to achieve justice. According to Theseus' words, the written laws ensure equality between rich and poor before justice ( $\sigma \theta \varepsilon v-\varphi \angle \pi \lambda o v \sigma l \Re \varphi \tau \varepsilon \tau-v \delta \square \kappa \eta v \square \sigma \eta v \square \chi \varepsilon$ 433434), the weak poor $(\angle \mu \varepsilon \square \omega v 437)$ can conquer the strong rich ( $\tau \Pi v \mu \square \gamma \alpha v 437$ ), if he has right ( $\left.\delta \square \kappa \alpha \imath^{\prime} \square \chi \omega v 437\right){ }^{23}$ The chorus of suppliants reassures the king of Athens after his decision to bury the dead; for as long as he preserves the light of justice ( $\tau \Pi \gamma \leq \rho \tau o$ r $\tau \mathfrak{I} \varphi \Delta \square \kappa \eta \varphi$ $\sigma(\imath \zeta \omega \nu \phi \leq o \varphi$ 564), he will avoid many accusations ( $\pi \circ \lambda \lambda o \Uparrow \varphi$ $\neg \pi \varepsilon \kappa \phi \vee \gamma o l \varphi \quad \psi \mathbb{R} \gamma o v \varphi 565)$. The chorus encourages him that justice is accompanied by success and victory; and the gods are with those who revere justice $(\delta \sqcap \kappa \eta v \sigma \square \beta O v \tau \alpha \imath$ 595), and give them victory ( $v \square \kappa \eta v \delta \square \delta \omega \sigma \imath v$ 596). Human will not benefit from courage only ( $\Upsilon \rho \varepsilon \tau-\delta^{\prime} o \wedge \delta \square v \phi \square \rho \varepsilon \imath \beta \rho o \tau o \square \sigma \imath v$ 596-597), unless it is accompanied by the gods' good will ( $\mu-\tau \Pi v \theta \varepsilon \Pi v \chi \rho \approx l \zeta o v \tau^{\prime} \square \chi \eta \imath$ 596).

When the suppliants doubt the justice of the gods $(\delta \imath \kappa \alpha \square o v \varphi$ $\delta \alpha \square \mu o v \alpha \varphi \sigma v \gamma^{\prime} \square v v \square \pi \varepsilon \imath \varphi$ 610) by making the gods responsible for Thebes' insolence against Argos' warriors, some suppliants answer that the people are to blame because justice calls for justice and blood demands blood ( $\delta \square \kappa \alpha \delta \square \kappa \alpha \nu \delta^{\prime} \square \kappa \leq \lambda \varepsilon \sigma \varepsilon \kappa \alpha \square \phi \Re \nu O \varphi \phi \AA \nu O v$ 614). The gods are not responsible for the unjust behavior of human beings; while people are committing their sins, the gods are patient and suddenly put an inevitable end of the people's misfortunes (615-617).

But after the victory of Athens over Thebes and burial of the dead, the

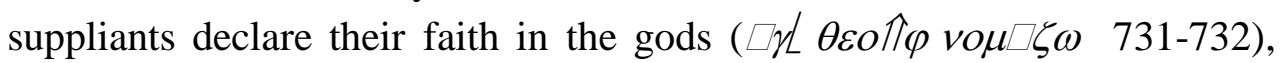
for having their cares reduced ( $\delta o \kappa(\tau f \varphi \sigma \nu \mu \phi o \rho f \varphi \square \chi \varepsilon \imath v$ 


\section{The Concept of Terms Related to Democracy in Euripides' Suppliant Women}

$\square \lambda \leq \sigma \sigma o v \varphi$ 732-733), after the unjust had been punished justly ( $\tau\langle v \delta \varepsilon \tau \varepsilon l \sigma \leq v \tau \omega v \delta[\kappa \eta \nu 733)$. This is confirmed by Adrastos, saying that it is foolish for humans to exceed the limits of injustice in the war $(o \square \tau @ \xi o v \square \square v \varepsilon \varepsilon \square v o v \tau \varepsilon \varphi \tau o \diamond \kappa \alpha \iota \rho o \diamond 744-745)$, because they will be punished badly by justice $(\pi \rho \Pi \varphi \delta \square \kappa \eta \varphi \gamma \varepsilon \pi \circ \lambda \lambda f \quad \pi \leq \sigma \chi \sigma \nu \tau \varepsilon \varphi \kappa \alpha \kappa f$ 746). Justice also was accompanied by truth and honesty, as Adrastos declares while talking about his dead comrades in the battle; so we must be just and honest while talking about people (' $\lambda \eta \theta \mathfrak{I} \kappa \alpha \square \delta \square \kappa \alpha \iota^{\prime}$ $\varepsilon \square \pi \varepsilon \square v \quad 859$ ).

The term $\square \sigma o v$ is also one of the terms of democracy, which expresses, in this play, the principle of equality as recognized by law in the democratic system. According to Theseus' praise to Athens; the city is free, and there is equality of the right-vote between the citizens without discrimination $\left(\square \lambda \varepsilon v \theta \varepsilon \rho\left(\sigma \alpha \varphi \tau \approx v \delta^{\prime} \square \sigma 囚 \psi \eta \phi o v \pi \circledast \lambda \imath v 353\right)\right.$, the people alternate to govern respectively ( $\left.\delta \Im \mu \circ \varphi \delta \jmath^{\prime} v \leq \sigma \sigma \varepsilon l \quad \delta l \alpha \delta o \chi \alpha \square \sigma l v 406\right)$, and the rich people have no privileges for their wealth $(o \wedge \chi \square \tau / \imath$ $\pi \lambda o v \tau \omega \iota \delta i \delta o \Uparrow \uparrow 407)^{24}$, and so there is equality between rich and poor in mounting positions $\left(\tau \prod \pi \lambda \varepsilon \square \sigma \tau o v ' \lambda \lambda f \chi l^{\prime} \quad \pi \sqcap v \eta \varphi \quad \square \chi \omega v \square \sigma o v\right.$ 406407). ${ }^{25}$ Thus the written laws ( $\gamma \varepsilon \gamma \rho \alpha \mu \mu \square v \omega v \delta \square \tau(v v \circledast \mu \omega v$ 433) ensure, in the democratic system, the equality of the weak poor and the strong rich in front of justice (' $\sigma \theta \varepsilon v-\varphi \angle \pi \lambda \sigma v \sigma \iota @ \varphi \quad \tau \varepsilon \tau-v \delta \square \kappa \eta v \square \sigma \eta v \square \chi \varepsilon l$ 433-434); and so equality permeated the state ( $\square \sigma \alpha \square \tau \varepsilon \rho o v \pi ® \lambda \varepsilon \varepsilon$ 441).

Freedom is one of the most fundamental pillars of democracy, and a basic product of the written laws. Freedom was expressed in the Suppliant Women by the Greek term $\square \lambda \varepsilon v \theta \varepsilon \rho \square \alpha$ among many expressions. On one hand, the king Theseus confirms that he freed the state $\left(\square \lambda \varepsilon v \theta \varepsilon \rho\left(\sigma \alpha \varphi \pi \Theta \lambda_{l v} \quad 353, \quad \square \lambda \varepsilon v \theta \square \rho \alpha \pi \Theta \lambda_{l v} \quad 405\right)\right.$, and applied

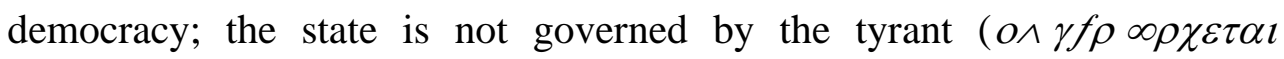
$\square v \prod \varphi \pi \rho \Pi \varphi{ }^{\prime} v \delta \rho \Pi \varphi$ 404-405), but the people are the ones who govern the state ( $\left.\delta \Im \mu \circ \varphi \delta \Im^{\prime} v \leq \sigma \sigma \varepsilon l 406\right)$. On the other hand, the messenger of the 


\section{Farid El-ANWAR}

dictatorship acknowledges that the state of Athens, under a democratic system, is a free state ( $\pi 囚 \lambda \iota v \square \lambda \varepsilon v \theta \square \rho \alpha v \square \chi \omega v 477)$.

The most important aspect of freedom is that every individual has freedom of speech and action, but on the condition that he is always listening to useful advice, which is expressed, in this play, by the Greek term $\varepsilon \wedge \beta o v \lambda \square \alpha$, as one of the basic principles of democracy. It is necessary for everyone to listen to useful advice from the experts before starting any work that may harm society such as war, as did the king of Argos, Adrastos, when he started a war with Thebes, without consulting the assembly of his people; he is led by his magnanimity instead of useful advice ( $\left.\varepsilon \wedge \psi v \chi \square \alpha v \square \sigma \pi \varepsilon v \sigma \alpha \varphi{ }^{\prime} v \tau^{\prime} \varepsilon \wedge \beta \sigma v \lambda \square \alpha \varphi 161\right) .{ }^{26}$ But as for the democratic Theseus, he must provide good reasons for his people ( $\lambda \square \gamma \omega v \kappa \alpha \lambda ® \nu 247)$, who have to agree with him about having war with the city of Thebes in order to bury the dead of Argos.

Therefore the freedom, in a democratic system, must be accompanied by other virtues, which are expressed by the terms of prudence and restraint ( $\sigma \vee v \varepsilon \sigma \iota \varphi 203)$, knowledge ( $\gamma \imath \gamma v(\sigma \kappa \varepsilon \iota v 204)$, and the ability to express opinion by tongue $(\gamma \lambda(\sigma \sigma \alpha \nu \lambda \AA \gamma \omega \nu \delta o v \varphi 204)$. And so, the mind and tongue are the tools of knowledge and the only way to resolve disputes rather than war.

There are many terms, in the play about the individual's free expression of his opinion which is useful for the country and avoiding remaining silent. The democratic Theseus demonstrates that it is a shame for the citizen to hide his opinion which is useful to his friends $\left(\alpha \square \sigma \chi \rho \Re \nu \gamma^{\prime} \square \lambda \varepsilon \xi \alpha \varphi, \chi \rho \approx \sigma \tau^{\prime} \square \pi \eta \kappa \rho v \pi \tau \varepsilon \imath \nu \phi \square \lambda o v \varphi 296\right)$.

And Queen Aithra asks her son not to be silent and express his opinion which is useful to the case of suppliants, saying that she will not fall silent ( $o \Leftarrow \tau o l \sigma \iota \omega \pi(\sigma \alpha 297)$ as a woman out of shyness, but she will not stop giving good advice ( $\varepsilon \otimes \lambda \square \gamma \varepsilon \varepsilon v$ 297), for fear of the belief that women's advice is useless (' $\chi \rho \varepsilon \square o v \tau f \varphi \gamma v v \alpha \square \kappa \alpha \varphi \delta \varepsilon \square \sigma \alpha \sigma^{\prime}{ }^{\prime} \phi \approx \sigma \omega \tau / \iota$ 


\section{The Concept of Terms Related to Democracy in Euripides' Suppliant Women}

$\phi \circledast \beta \omega \iota$ 299-300). ${ }^{27}$ Euripides supports that women, in the democratic system, must have an equal right to men to express their opinion. ${ }^{28}$

The King agrees to his mother's advice ( $\angle \rho / \delta \square \kappa^{\prime} \gamma \downarrow \tau \alpha \Delta \theta^{\prime}$ $/ \pi \varepsilon \rho \mu \varepsilon \operatorname{vov} \theta \varepsilon \tau \varepsilon \square \varphi 337)$ and promises to show his opinion about the suppliants' issue $\left(\gamma v\left(\mu \eta v \neg \phi^{\prime} \quad o \square \omega v \square \sigma \phi \leq \lambda \eta \beta o v \lambda \varepsilon v \mu \leq \tau \omega v \quad 335-336\right)\right.$. Theseus confirms, in his interview with the messenger of Thebes' dictator, that freedom of expression is guaranteed for all, and declares that through the important principle of democracy: "Speak and do not be silent" ( $\lambda \square \gamma \varepsilon, \ldots$ o^ $\sigma l \gamma \eta \lambda \Pi \varphi \varepsilon \square 567)$. And the messenger of Thebes agrees stating that each person must participate in conversation ( $\delta \varepsilon \square \delta o \mho v \alpha \imath \mu \square \rho o \varphi 570$ ).

One of the positive points about democracy is that it gives equal share in public deliberation, but democracy places a condition for the freedom of expression ( $\tau 0 \wedge \lambda \varepsilon \vee \theta \varepsilon \rho o v 438)$ : every one having a useful view for the state $(\chi \rho \eta \sigma \tau ® \nu \tau \imath \beta o v \lambda \varepsilon v \mu \alpha 439)$ must show it and so he will get a good reputation $(\angle \chi \rho \approx \tau \zeta \omega v \lambda \alpha \mu \pi \rho \otimes \varphi$ 440), otherwise it is better to remain silent $\left(\angle \mu-\theta \square \lambda \omega v \sigma l \gamma \boldsymbol{v}_{l} 441\right) .{ }^{29}$

Democracy places another condition: the freedom of speaking must be accompanied by the power of persuasion ( $\lambda ® \gamma o l \sigma l \pi \varepsilon \square \theta \omega \nu$ 347), as Theseus explains that he will use the power of persuasion in his dialogue with the king of Thebes before the war, but if he refuses his request for burying the dead, at once he will try to convince ( $\pi \varepsilon \square \sigma \alpha \varphi \tau \leq \delta \varepsilon 355)$ the assembly of his people until they agree to his war. Adrastos begs also States to have a discussion as a way to stop their evils ( $\pi ® \lambda \varepsilon l \varphi \tau^{\prime}$, $\square \chi o v \sigma \alpha l \delta$ if $\lambda \Theta \gamma o v \kappa \leq \mu \psi \alpha l \kappa \alpha \kappa \leq 748)$, and to prefer speaking to murder in resolving their issues $\left(\phi \circledast \nu \omega \imath \kappa \alpha \theta \alpha \imath \rho \varepsilon \square \sigma \theta^{\prime} \quad\right.$ o^ $\lambda \Theta \gamma \omega \imath \tau f \pi \rho \leq \gamma \mu \alpha \tau \alpha$ 749).

The work, effort, and tasks are the actual means to achieve the principles of democracy, which have been released through the following terms: $\pi ® \nu o \varphi$ (e.g. 317, 323, 373), $\mu ® \chi \theta \eta \mu \alpha$ (1187). The queen Aithra stimulates her son, saying that if he finds an opportunity to show his 


\section{Farid El-ANWAR}

proficiency in the service of his country, he must exploit it and he should not be a coward ( $\chi \rho \mathfrak{I} v \square \kappa \pi o v \mathfrak{T} \sigma \alpha \iota \delta \varepsilon \imath \lambda \Pi \varphi\{v \square \phi \eta v \rho \square \theta \eta \varphi 319)$, and he has to work hard to advance his position $\quad(\square v \gamma f \rho \tau o \square \varphi$ $\pi \AA v o l \sigma \imath v \alpha \Leftarrow \xi \varepsilon \tau \alpha \imath 323)$.

Democracy has identified this work with the adjective " $\varepsilon \wedge \sigma \varepsilon \beta-\varphi$ " (373) which shows that it must be pious act for the benefit of society without any personal goals. The chorus of suppliants shows that pious work is such a beautiful statue which decorates the cities $\left(\kappa \alpha \lambda \Pi v<\delta^{\prime}>\right.$ $\infty \gamma \alpha \lambda \mu \alpha \pi \Re \lambda \varepsilon \sigma \imath v \varepsilon \wedge \sigma \varepsilon \beta-\varphi \pi \Re \nu \circ \varphi 373)$, and requires gratitude forever ( $\chi \leq \rho \imath v \tau^{\prime} \square \chi \varepsilon \imath \tau f v \square \varphi \alpha \square \varepsilon \square 374$ ). The chorus here implicitly suggests that the democratic Theseus' work which is burying the dead, is pious act that deserves good reward. ${ }^{30}$ One of the first external tasks is that mission of ambassadors who are experts at delivering various letters of the State to the other countries. For example, Theseus praises the Athenian envoy, whom he sends to the city of Thebes as his experience served the state and its ruler $\left(\tau \square \chi v \eta v \mu \square v \alpha \square \varepsilon \square \tau \approx v \delta^{\prime} \square \chi \omega v \quad \neg \pi \eta \rho \varepsilon \tau \varepsilon \square \varphi \quad \pi 囚 \lambda \varepsilon \imath \tau \varepsilon \kappa^{\prime} \mu o \square 381-382\right)$, by transferring their reports to the other various countries ( $\delta \iota \alpha \phi \square \rho \omega v \kappa \eta \rho v \gamma \mu \alpha \tau \alpha 382)$.

The democratic system was interested in the middle class as Theseus explains that the State is made up of three classes: 1- The highest, the rich are useless for their country ( $\left.o \square \mu \square v{ }^{T M} \lambda \beta \imath o{ }^{\prime}{ }^{\prime} v \omega \phi \varepsilon \lambda \varepsilon \square \varphi \quad 238-239\right)^{31}$, as they are always craving for more ( $\pi \lambda \varepsilon \imath \circledR v \omega \nu \tau^{\prime} \square \rho\left(\sigma^{\prime}{ }^{\prime} \varepsilon \square 239\right)$. 2- The lowest, the poor ( $O \square \delta^{\prime} O \wedge \kappa \square \chi O \nu \tau \varepsilon \varphi 240$ ) who have no source of income ( $\sigma \pi \alpha \nu \square \zeta o v \tau \varepsilon \varphi \beta \square$ ov 240) and are dangerous, as they are controlled by envy and hatred ( $\delta \varepsilon \imath v o \square, v \square \mu o v \tau \varepsilon \varphi \tau(\imath \quad \phi \theta \ll \nu \omega \imath \pi \lambda \square o v \mu \square \rho o \varphi$ 241), which drive them to commit evils against the rich $\left(\square \varphi \tau o v \varphi<\tau^{\prime}>\right.$ $\square \chi o v \tau \alpha \varphi \kappa \sqsubset v \tau \rho '$ ' $\phi \imath \vee \sigma \imath v \kappa \alpha \kappa \leq 242) .{ }^{32}$ These poor are misled by the

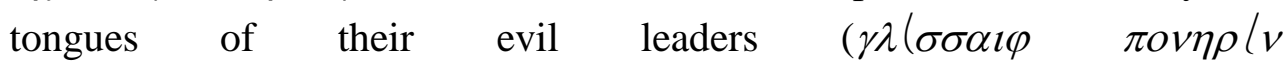
$\pi \rho o \sigma \tau \alpha \tau(v \phi \eta \lambda o v \mu \varepsilon v o r 243) .{ }^{33} 3$ - The middle, the people who preserve the state $(\neq \ni v \mu \square \sigma \omega \imath \sigma(\imath \zeta \varepsilon \imath \pi \Re \lambda \varepsilon \imath \varphi 244)$ and protect the order in the 


\section{The Concept of Terms Related to Democracy in Euripides' Suppliant Women}

country and stability in society $(\phi \nu \lambda \leq \sigma \sigma o v \sigma \ni \odot v \tau \imath \nu \ni \bullet v \leq \xi \xi \eta \pi ® \lambda \imath \varphi$ $245){ }^{34}$ The people of this class are the men of moderate wealth and moderation, and are not greedy like the rich or envious like the poor, but they have cooperative moral values such as sanity, restraint and conviction, which qualify them to apply the principles of democracy: justice, freedom, equality and social solidarity. ${ }^{35}$

In order to have social peace between the rich and the poor, there must be social solidarity, as the democratic system aims. Adrastos, encouraging both the rich and the poor, declares that it is wise for rich and poor, fortunate and unfortunate, to watch each other's actions

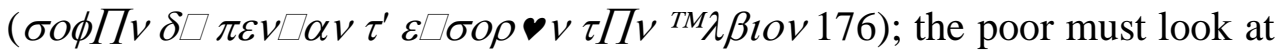
the rich ambitiously ( $\pi \square v \eta \tau \leq \tau \ni \square \varphi \tau o \Uparrow \varphi \quad \pi \lambda o v \sigma \square o v \varphi{ }^{\prime} \pi o \beta \lambda \square \pi \varepsilon l v$, $177)$ in order that he may long for wealth $\left(\zeta \eta \lambda \diamond \diamond v \theta^{\prime}, \square v^{\prime}\right.$ $\left.\alpha \wedge \tau \prod v \chi \rho \eta \mu \leq \tau \omega v \square \rho \omega \varphi \square \chi \eta \eta, 178\right)^{36}$, and the rich must care about the poor $(\tau \leq \tau \ni o \square \kappa \tau \rho f \tau o \Uparrow \uparrow \varphi \mu-\delta v \sigma \tau v \chi \varepsilon \square \varphi \delta \varepsilon \delta o \rho \kappa \square v \alpha \iota 179) .{ }^{37}$

Adrastos' words seem to be tending in direction of trying to Theseus help the suppliants and himself on the grounds that the king may one day find himself in their position, as every rich loses his wealth for changing his fate. ${ }^{38}$ The two verbs "' $\pi \rho \beta \lambda \square \pi \varepsilon l v, \delta \varepsilon \delta o \rho \kappa \square v \alpha l$ " play an important role in achieving social solidarity; both the care and the ambition guarantee this solidarity and lead to a renaissance of the community.

\section{Negative Aspects of the Democratic System}

The play's terms show also negative aspects of the democratic system. These negatives are shown through the behavior of the People's Congress leaders who mislead people with their tongues' eloquence and false promises in order to obtain a private gain, at expense of the public good. For example, Theseus illustrates, in his speech to Adrastos, that the reasons of his people's defeat are due to the negative aspects within the community itself; from the abusive behaviors of individual such as: seeking power and misusing it $\left(\angle \delta^{\prime}(\varphi \neg \beta \rho \square \zeta \eta \imath \delta \vee v \alpha \mu \iota v \square \varphi \quad \chi \varepsilon \sqcap \rho \alpha \varphi \lambda \alpha \beta(v \quad 235)\right.$, and 


\section{Farid El-ANWAR}

waging war only for the sake of gain $(\kappa \square \rho \delta o v \varphi o \Leftrightarrow v \varepsilon \kappa 236)^{39}$, neglecting the people's good, the extreme ambition and the harm coming out of it.

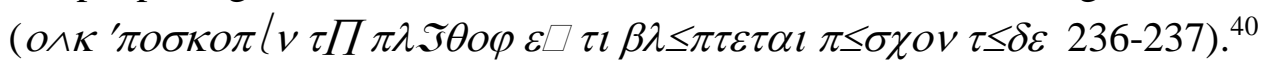

Theseus' criticism may be directed against Alcibiades, and the contemporary Athenian democracy of the $5^{\text {th }}$ Cent. B.C. ${ }^{41}$ Theseus describes the forceful and selfish pressure of the young hotheads in Argos in ways that seem very similar to Thucydidean view of some of the young Athenian politicians. The $\Leftrightarrow \beta \rho \imath \varphi$ of one typical such young men; who are held to put private ambitions and profit before the security of citizens as a whole, this leads to praise of the moderates as the main source of stability and order for the state $(245){ }^{42}$

The Messenger of dictatorial Thebes declares that governance of the mob ( $\left.{ }^{T M} \chi \lambda \omega \imath \kappa \rho \alpha \tau \vee v \varepsilon \tau \alpha \imath 411\right)$ is one of the most important democratic system negatives, and this leads to the appearance of some leaders who

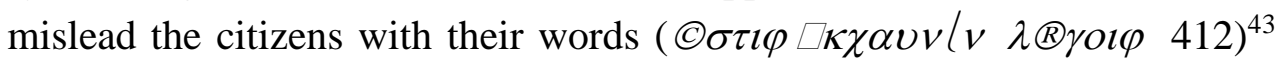
for their private gain $(\pi \rho \Pi \varphi \kappa \square \rho \delta o \varphi \square \delta i o v 413) .{ }^{44} \quad$ They cover their previous mistakes with new lies ( $\delta \imath \alpha \beta o \lambda \alpha \square \varphi v \square \alpha \imath \varphi \kappa \lambda \square \psi \alpha \varphi 415-416) .{ }^{45}$ Then they escape from the punishment of justice $(\square \xi \square \delta v \delta \square \kappa \eta \varphi 416) .{ }^{46}$ And so the demagogue's habitual use of $\delta i \alpha \beta o \lambda \alpha \square \varphi$ confirms the truth of Theseus' concern that such a leader might exacerbate the resentments of the poor against the rich $(242-243) .{ }^{47}$

The principle, that citizens from the public $(\delta \mathfrak{I} \mu \circ \varphi \varepsilon \wedge \theta \vee v \varepsilon \imath \nu$ $\pi 囚 \lambda \iota v 418)$ govern the state, leads to the existence of a ruling class that is not able to manage the affairs of the country properly $(\mu-\delta i o \rho \theta \varepsilon v \omega v$ $\lambda ® \gamma o v \varphi \nabla \rho \theta(\varphi \delta v v \alpha \imath \tau o$ 417-418). For example, it is not suitable for a poor ignorant peasant $\left(\gamma \alpha \pi \Re \nu O \varphi \delta^{\prime}{ }^{\prime} \nu-\rho \pi \square \nu \eta \varphi, \mu-{ }^{\prime} \mu \alpha \theta \approx \varphi 420-421\right)$ to ascend the political office for his lack of political culture, as a result of the nature of his work, and then cannot manage the public affairs of the country $\left(o \wedge \kappa \diamond v \delta v v \alpha \imath \tau o \pi \rho \prod \varphi \tau f \kappa O \square v \ni ' \pi o \beta \lambda \square \pi \varepsilon \imath v\right.$ 422). And also it is not convenient for a crafty man who has no value before ( $\pi \circ v \eta \rho \Pi \varphi, \ldots o \wedge \delta \square v\{v \tau \Pi \pi \rho \square v 424-425)$, to get a political office of high 


\section{The Concept of Terms Related to Democracy in Euripides' Suppliant Women}

esteem by wooing the people with his tongue (' $\xi \square \omega \mu{ }^{\prime}$ ' $\nu-\rho$

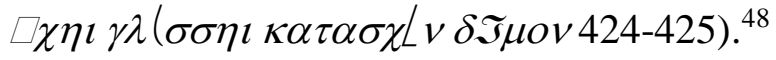

The Messenger of dictatorial Thebes criticizes the decision of war which was taken by Athens against Thebes and explains negatives of the public's control on the decision of war; the spirit of people and the equality of the vote may lead to damage, especially when the consensus of people vote for a war, this may lead to destruction. Euripides halts the action while he permits the founder of Athenian democracy to wrangle with an impudent herald on such topics for debate as resolved that "there is more evil than good in the world", "the vanity of human ambition", "tyranny versus democracy", "war versus peace". ${ }^{49}$

When the people vote for war, (C $\tau \alpha \nu \gamma f \rho \square \lambda \theta \eta \imath \pi \AA \lambda \varepsilon \mu o \varphi$ $\square \varphi \psi \mathfrak{T} \phi o v \lambda \varepsilon(481)$, no man thinks that his own death may be in his vote, as result of this war ( $\left.\wedge \wedge \delta \varepsilon \square \varphi \square \theta^{\prime} \alpha \neg \tau o \downarrow \theta \leq v \alpha \tau o v \square \kappa \lambda o \gamma \square \zeta \varepsilon \tau \alpha \iota 482\right) .{ }^{50}$ And every one casts reason of the defeat on the other ( $\tau \Pi \delta v \sigma \tau v \chi \square \varphi \delta \square \tau o \downarrow \tau^{\prime} \square \varphi \infty \lambda \lambda o v \square \kappa \tau \rho \square \pi \varepsilon \imath$ 483); if they imagine death with their own eyes during the vote $\left(\varepsilon \square \delta^{\prime}\right.$ fov $\pi \alpha \rho^{\prime}$ $\left.{ }^{T M} \mu \mu \alpha \theta \leq v \alpha \tau O \varphi \square v \psi \approx \phi o v \phi o \rho v_{\imath} 484\right)$, they will go back on the ill-fated decision, and so Greece would not rush to mad desire for the destruction of war $\left(o \wedge \kappa \infty \nu \pi o \theta^{\prime} \quad \bar{E} \lambda \lambda f \varphi \delta o \rho \imath \mu \alpha \nu-\varphi{ }^{\prime} \pi(\lambda \lambda \nu \tau O \quad 485){ }^{51}\right.$ It is part of Euripides' concern in this play to demonstrate uncertainty of human life, and man's ignorance of the outcome of his acts. ${ }^{52}$

III. Criteria for the election of the leader and demagogues in democracy

The terms of the Suppliant Women show also the characteristics which should be available in the ideal leader and the demagogues, according to the democratic system. This play involves many features of democracy and tyranny, but both styles of government depend mainly on the qualities of leadership. We find some of these characteristics or qualities on the lips of the Apostle when he praises Theseus the democratic 


\section{Farid El-ANWAR}

leader, saying that the people should elect such a leader $(\tau O \imath \circledast v \delta \varepsilon \tau O \imath \sigma \tau \rho \alpha \tau \eta \gamma \Pi v \alpha \square \rho \varepsilon \square \sigma \theta \alpha \imath \chi \rho \varepsilon(v$ 726), then he declares the attributes of his personality: a brave man in the midst of serious crises ( $\sqrt{ } \varphi \square v \tau \varepsilon \tau \sigma \square \varphi \delta \varepsilon \imath v o \square \sigma \square v \square \sigma \tau \imath v \infty \lambda \kappa \imath \mu o \varphi 727$ ), despises the arrogant countries $(\mu \iota \sigma \varepsilon \square \theta \ni \neg \beta \rho \imath \sigma \tau-v \lambda \alpha \Re \nu 728)^{53}$, sacrifices life's goods ( $\zeta \eta \tau / v^{\prime} \pi\left(\lambda \varepsilon \sigma^{\prime}{ }^{T M} \lambda \beta O v\right.$ 730), for reaching to the highest degree of glory ( $\square \varphi \infty \kappa \rho \alpha \beta \Im v \alpha \imath \kappa \lambda \iota \mu \leq \kappa \omega v \square v \approx \lambda \alpha \tau \alpha$ 729). ${ }^{54}$ These expressions contrast Theseus, the ideal leader in peace and war, with Adrastos, who is led by the young hotheads, and equally the overconfident Thebes, as clear contrast between good and bad causes for wars. ${ }^{55}$

Adrastos has more characteristics that must be met in leader's personality, as criteria of the human' merits, when he talks about his dead friends: the first is not arrogance ( $\phi \rho 尺 \nu \eta \mu \alpha \delta \square o \wedge \delta \square v$ 862-863), lack of careerism and escape from the tables of bribery ( $\phi \varepsilon \vee \gamma \omega v \tau \rho \alpha \pi \square \zeta \alpha \imath \varphi 864)$,

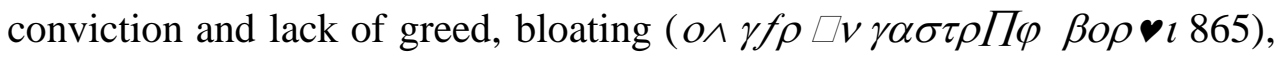
moderation $(\mu \square \tau \rho i \alpha$ 866). The second is rich with honor ( $\pi \lambda \varepsilon \sqcap \sigma \tau \alpha \varphi \tau \imath \mu f \varphi$ 874), refused to the material aid ( $\chi \rho v \sigma \Pi \nu o \wedge \kappa \varepsilon \square \sigma \varepsilon \delta \square \xi \alpha \tau \ni o \square \kappa o v 875-876$ ), so as not to become a slave to money ( $\delta \circ \vee \lambda o v \varphi \chi \rho \eta \mu \leq \tau \omega v 877$ ). The third is an ambitious character $(\phi \imath \lambda \AA \tau \imath \mu о v$ \& $\theta \circ \varphi$ 907), has a vigor in the act, not to speak

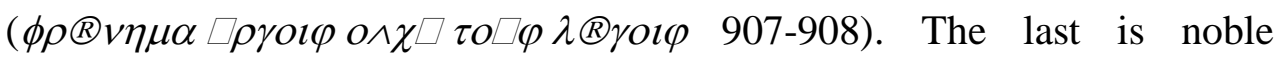
breeding ( $\tau \Pi \gamma f \rho \tau \rho \alpha \phi \mathfrak{T} v \alpha \imath \mu-\kappa \alpha \kappa(\varphi \alpha \square \delta(\phi \square \rho \varepsilon \imath$ 911), grew up well ( $\tau \rho \alpha \phi \mathfrak{I} v \alpha \imath \mu-\kappa \alpha \kappa(\varphi 912)$, and so he used to practice virtue in order to shame from the commission of vice $\left(\tau^{\prime} \gamma \leq \theta \ni{ }^{\prime} \sigma \kappa \approx \sigma \alpha \varphi \quad{ }^{\prime} \nu-\rho\right.$, $\alpha \square \sigma \chi v v \varepsilon \tau \alpha \imath \kappa \alpha \kappa \prod \varphi$ 912-913).

\section{Conclusion}

Thus, we can conclude that there is no doubt that the terms which reflect the principles of democracy, such as justice, equality, freedom and law, play an important role in the dramatic events, it has been a driving force pushed the democratic king of Athens, who believes in these 


\section{The Concept of Terms Related to Democracy in Euripides' Suppliant Women}

principles, to be convinced of the justice of the Suppliants' case to bury their sons and waged war with city of Thebes to achieve justice and equality in the rights whom guarantee the laws of democracy.

On one hand, Euripides praises, in those terms, the positive aspects of the democratic system which represents the cooperative moral values, which benefit the individual and society, such as justice, equality, freedom, self-restraint, moderation, prudence, conviction, useful advice and piety. But on the other hand, Euripides criticizes bad behaviors, such as extreme ambitions, the love of gain at expense of the public good, the love of power, greed, bribery, careerism, which leads to corruption and destroying of the economic construction, social and moral in the society.

And so the people should choose carefully their deputies, whether as governor or demagogues, and should not be misled by the bright promises and false words. They must choose the fittest, regardless of his competitive values, such as origin, wealth, social status, but who has moral values that may benefit the individual, the family and all the state, internally and externally. Finally the play supports that the people should elect someone accustomed to practice of virtue, and has modesty from committing of vice.

\section{Notes}

1 A version of this paper was read in the ninth International Conference "Drama and Democracy" of Department of Greek and Latin Studies, Faculty of Arts, Cairo University in March 2012; I am grateful to participants in the conference for their stimulating feedback.

2 For the transition from dictatorship to democracy, see K. A. Raaflaub, "Contemporary Perceptions of democracy in Fifth Century Athens", ( $C \& M 40$ (1989), 33-70), esp. for Supp. pp. 45-46, ___, " Democracy, Oligarchy, and the Concept of the "Free Citizen" in Late Fifth-Century Athens", (Political Theory Vol. 11 no. 4 (1983), 517-544), for Supp. p. 520. A.E.Haigh, The Tragic Drama of The Greeks (Dover, New York 1968), pp. 274-276.

3 For Euripides and politics, see W. J. M. Starkie, "Euripides the Politician", ( $Q R$ 9 no. 34 (1920) 195-212).

4 For praise of Athens in Greek tragedy generally, see L.V.Hook, "The Praise of Athens in Greek Tragedy", (CW 27 no. 24 (1934), 185-188). 


\section{Farid El-ANWAR}

${ }^{5}$ For personality of Theseus, see M.H.Shaw, "The $\tilde{\eta} \theta 0 \varsigma$ of Theseus in 'The Suppliant Women", Hermes 110 (1982) 3-19). J. N. Davie, "Theseus the King in Fifth-Century Athens", ( $G \& R$ s.s. 29 no. 1 (1982) 25-34).

${ }^{6}$ P. J. Rhodes supports (Nothing to Do with Democracy: Athenian Drama and the Polis, J HS 123, 2003, pp. 105, 113) that Euripides' Supplices was a defense of the democracy.

${ }^{7}$ V. Parker declares (" Tv $\rho \alpha v v o \varphi$. The Semantics of a Political Concept from Archilochus to Aristotle, Hermes 126, 1998, p. 160) that the play makes a debate on the advantages and disadvantages of one-man rule; and this debate clearly revolves about this general topic and not any particular form of monarch.

${ }^{8}$ Cf. Hdt. III. 80. 25-28:

$\Pi \lambda \Im \theta \circ \varphi \ldots \pi \leq \lambda \vartheta \mu \square v \gamma f \rho ' \rho \chi f \varphi \infty \rho \chi \varepsilon l, \neg \pi \varepsilon v \theta v v o v \delta \square \rho^{\prime} \rho \chi v \square \chi \varepsilon l$,

${ }^{9}$ See A. N. Michelini, "Political Themes in Euripides' Suppliants", (AJPh 115 no. 2 1994), pp. 232-233.

${ }^{10}$ B. Sarachek explains ("Greek Concepts of Leadership", (AMJ 11 no. 1 (1968) p. 45) that because the tyrant must preserve his own position, he fears and must eliminate the newer, more capable leaders who might arise under him, while a democracy may utilize these new leaders and their advice to good advantage. Finally, the tyrant tends to destroy initiative because he may lay claim to things belonging to his subjects at any time. See also Shaw, "The $\tilde{\eta} \theta$ os of Theseus in 'The Suppliant Women", p. 4.

For the $\tau \vee \rho \alpha v v o \varphi$ in view of the democratic system, see:

V.J.Rosivach, "The Tyrant in Athenian Democracy", (Quaderni Urbinati di Cultura Classica n.s. 30 no. 3 (1988) 43-57).

${ }^{11}$ See E.M. Thury, "A Study of Words Relating to Youth and Old Age in the Plays of Euripides and Its Special Implications for Euripides' "Suppliant Women", (Computers and the Humanities 22 No. 4 1988), p. 304.

${ }^{12}$ Cf. Xen. Hist. Ath. Resp. 1.8. 4-6:

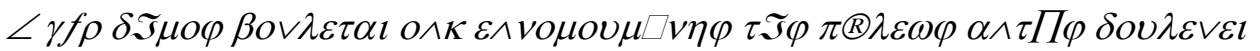
$v$,

' $\lambda \lambda^{\prime} \square \lambda \varepsilon \vee \theta \varepsilon \rho o \varphi \varepsilon \square v \alpha \imath \kappa \alpha \square \infty \rho \chi \varepsilon \imath v$. "The people do not want a good government under which they themselves are slaves; they want to be free and to rule".

See Raaflaub, "Democracy and the Concept of the Free Citizen", 520. Michelini, "Political Themes in Euripides' Suppliants", p. 235. R. B. Gamble, "Euripides' Suppliant Women: Decision and Ambivalence", (Hermes 98 no. 4 1970), p. 400. 


\section{The Concept of Terms Related to Democracy in Euripides' Suppliant Women}

${ }^{13}$ D.M. MacDowell, ("Hybris in Athens", $G \& R$ n.s. 23 no. 1, 1976, p. 26) explains that the word nomos in legal con-texts had come to mean exclusively written law; for at the end of the fifth century a law had been made forbidding the enforcement of laws not officially inscribed.

${ }^{14}$ B. Sarachek explains (Greek Concepts of Leadership, AMJ 11 no. 1 1968 , p. 45) that in the Suppliants, Euripides specifies the advantages of democratic rule over the sort of tyranny found in Creon's Thebes. He points out that the authoritarian becomes a law unto himself, and this leads to unfair and unequal treatment of subjects. See also Shaw, "The $\tilde{\eta} \theta$ os of Theseus in 'The Suppliant Women", p. 4.

${ }^{15}$ For the concept of law and justice in democracy, cf. Eur. Tr. 1029-1032, Elec. 1268-1269, Or. 564ff., Soph. Elec.577ff. See A.W.H.Adkins, Moral Values and Political Behavior in Ancient Greece from Homer to the end of the Fifth Century (London 1972), 103-106.

${ }^{16}$ See D. J. Conacher, "Religious and Ethical Attitudes in Euripides' Suppliants", (TAPhA 87 1956), p. 20.

${ }^{17}$ For the funeral ritual in this play and the recovery of the dead warriors, see M.Toher, "Euripides' Supplices and the Social Function of Funeral Ritual", (Hermes 129 (2001) 332-343).

${ }^{18}$ D. J. Conacher suggests (Rhetoric and Relevance in Euripidean Drama, $A J P h$ 102 no. 1 1981, p. 24) that Theseus goes to war with the Thebans in defense of that same "well-ordered universe". This is the point of his repeated claims to the Theban Herald later that he is championing the ancient law of the gods (563) and the international law of all the Greeks (671) in insisting, by force if necessary, that the Thebans allow burial of the enemy dead. See also J.E.G. Whitehorne,"The Dead as Spectacle in Euripides' Bacchae and 'Supplices", (Hermes 114 1986), p. 68

${ }^{19}$ Gamble (Euripides' Suppliant Women, p. 402) explains that Theseus' references to his desire to maintain the Pan-Hellenic law are excluded because they may be taken to imply solely that he maintains it because this is essential to the continuation of the virtue of courage in Greece (537 ff.), and not to suggest piety in particular. See also Conacher, "Religious in Euripides' Suppliants", p. 20.

${ }^{20}$ For the Law and Order in Athens, see D.Cohen, Law, Violence, and Community in Classical Athens (Cambridge Univ. Press 1995), esp. pp. 3-24.

${ }^{21}$ See Conacher, "Religious in Euripides' Suppliants", p. 15.

${ }^{22}$ See M.McDonald, Terms for Happiness Euripides (Hypomnemata 54. Gottingen 1978), p. 109. 


\section{Farid El-ANWAR}

${ }^{23} \mathrm{Cf}$. Theog. 177-178, where the man, for his poverty, has not freedom of speech and act: $\kappa \alpha \square \gamma f \rho ' v-\rho \pi \varepsilon v \square \eta \imath \delta \varepsilon \delta \mu \eta \mu \square v o \varphi o \Leftarrow \tau \varepsilon \tau \imath \varepsilon \square \pi \varepsilon \square v$ $o \Leftarrow \theta^{\prime} \square \rho \xi \alpha l \delta \vee v \alpha \tau \alpha l$,

See Adkins, Moral Values and Political Behavior, pp. 104-105, 127. McDonald, Terms for Happiness Euripides, pp. 106-107.

${ }^{24}$ For the principle that there is no distinction of wealth in democracy, cf. Eur.fr. 362.7-8: $\tau 7 \pi \lambda o v \sigma \square \vartheta \tau \varepsilon \tau 7 \tau \varepsilon \mu-\delta \imath \delta o \Uparrow \varphi \mu \square \rho o \varphi \square \sigma o v$

Eur. fr. 626.1-2: $\delta \approx \mu \vartheta \delta \square \mu \approx \tau \varepsilon \pi \vee v^{\prime} v \alpha \rho \tau \approx \sigma \varsigma \varphi \kappa \rho \leq \tau O \varphi$

$$
\mu \approx \tau^{\prime} \alpha \Theta \kappa \alpha \kappa(\sigma \varsigma \varphi, \pi \lambda \circ \diamond \tau o v \square v \tau \imath \mu o v \tau \imath \theta \varepsilon \square \varphi,
$$

${ }^{25}$ For the term " $\square \sigma o v "$ Michelini ("Political Themes in Euripides' Suppliants", p. $235)$ explains that the word $\square \sigma o v$ bears enormous weight in Theseus' formulation of democratic ideology. See also C.S. Yialoucas, The Conflict of $\Delta \circledR \xi \alpha$ and $A \lambda \approx \theta \varepsilon \iota \alpha$ in Euripides and Predecessors (Ph.D. University of California 1981), pp. 143-144.

${ }^{26}$ See Michelini, "Political Themes in Euripides' Suppliants", pp. 235. W.D.Smith, "Expressive Form in Euripides' Suppliants", (HSCPh 71 1967), p. 158. Shaw, "The $\tilde{\eta} \theta 0 \varsigma$ of Theseus in 'The Suppliant Women", p. 5.

${ }^{27}$ See Conacher, "Religious in Euripides' Suppliants", p. 21.

${ }^{28}$ For the position of woman in Athenian law and democracy, see R.Just, Women in Athenian Law and Life (London and New York 1989), esp. p. 22, where Just declares that although it is unlikely that the position of women in Athens underwent any substantial decline as a result of the democracy, the observation sometimes made that women's position was worse during the democracy than in earlier periods, and worse in Athens than in other states. In monarchic states, the women who belonged to the elite have often wielded considerable power, but in the Athenian democracy there no thrones from behind which women could rule.

29 Cf. Eur. Hipp. 421-425, where Euripides praises freedom of speech $(\pi \alpha \rho \rho \eta \sigma \square \alpha)$ as result of true freedom in democracy. See Michelini, "Political Themes in Euripides' Suppliants", pp. 231-232. Adkins, Moral Values and Political Behavior, pp. 104-105, 142.

${ }^{30}$ For the pious act " $\varepsilon \wedge \sigma \varepsilon \beta-\varphi \pi \AA v o \varphi$ " and honor in democracy, see Gamble, "Euripides' Suppliant Women", pp. 402-403.

${ }^{31}$ For the useless rich, cf. Eur. Heracl. 3-4:

$$
\angle \delta^{\prime} \square \varphi \tau \Pi \kappa \square \rho \delta o \varphi \lambda \Im \mu^{\prime} \quad \square \chi \omega v^{\prime} v \varepsilon \imath \mu \square v o v \pi \AA \lambda \varepsilon \imath \tau^{\prime}
$$

$\infty \chi \rho \eta \sigma \tau о \varphi$,

$$
\text { fr. 641.2: } \square v \tau 7 \gamma f \rho^{T M \lambda \beta \vartheta ~ \phi \alpha v \lambda ® \tau \eta \varphi \square v \varepsilon \sigma \tau \square \tau \iota \varphi,}
$$

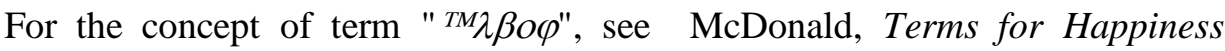
Euripides, p. 104. 


\section{The Concept of Terms Related to Democracy in Euripides' Suppliant Women}

${ }^{32}$ Cf. Plut. Nik. 11.2.3-5: $\tau \prod \nu \delta \square N \imath \kappa \square \alpha v @ \tau \varepsilon \pi \lambda o \downarrow \tau O \varphi \square \pi \square \phi \theta o v o v \square \pi \sigma \square \varepsilon l$, $\kappa \alpha \square \mu \leq \lambda \iota \sigma \tau \alpha \tau \Im \varphi \delta \imath \alpha \square \tau \eta \varphi \tau \prod \mu-\phi \imath \lambda \leq v \theta \rho \omega \pi \sigma v \mu \eta \delta \square \delta \eta \mu o \tau \imath \kappa \circledR v, \quad$ where Plutarch relates that the Athenian demos was hostile to the wealthy.

And for the thought that poverty, as disease, teaches the evil, cf. Eur. Elec. 375-376:

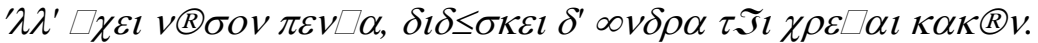

See P.Burian, "Logos and Pathos: The Politics of Suppliant Women": Directions in Euripidean Criticism. A Collection of Essays (Duke University Press, Durham 1985), p. 133.

${ }^{33}$ For the evil leaders and their role in misleading the people, see D.Rosenbloom, "From Ponêros to Pharmakos: Theater, Social Drama, and Revolution in Athens, 428-404 BC", (Cl Ant 21 no. 2 (2002) 283-346), esp. 292. For a familiar expressions, cf. Eur. 1288: $\gamma \lambda(\sigma \sigma \eta \varphi \pi \imath \kappa \rho o \square \varphi \kappa \square v \tau \rho o \imath \sigma \iota \kappa \lambda \eta \imath \delta o v \chi o v \mu \varepsilon v o l$.

IA.333: $\varepsilon ® \kappa \varepsilon \kappa \circledR \mu \psi \varepsilon v \sigma \alpha \imath \pi o v \eta \rho \leq \cdot \gamma \lambda\left(\sigma \sigma^{\prime} \square \pi \square \phi \theta o v o v \sigma o \phi \approx\right.$

Or.772: $\delta \varepsilon \imath v \prod v o \square \pi \sigma \lambda \lambda \sigma \square, \kappa \alpha \kappa o v \rho \gamma o v \varphi$ ○ $\tau \alpha v \square \chi \omega \sigma \imath \pi \rho o \sigma \tau \leq \tau \alpha \varphi$.

Soph. Ai.198-199: $\pi \leq v \tau \omega v \kappa \alpha \gamma \chi \alpha \zeta ® v \tau \omega v \gamma \lambda\left(\sigma \sigma \alpha \iota \varphi \beta \alpha \rho v \leq \lambda \gamma \eta \tau^{\prime}\right.$.

${ }^{34}$ D.K.Roselli ("Gender, Class and Ideology: The Social Function of Virgin Sacrifice in Euripides' Children of Herakles", Cl Ant 26 no. 1 2007, p. 99), suggests that despite the reference in Euripides' Suppliants to the "middle" group that "saves cities", it seems to promote a general group mentality, designed apparently to promote common interests yet supportive of the status, the idea of a "middling group" could thus be useful by offering a pleasing illusion of a community lacking in or reconciling class antagonism.

See also J.T. Sheppard, " Tv $\rho \alpha v v o \varphi, K \square \rho \delta o \varphi$, and the Modest Measure in Three Plays of Euripides", (CQ 11 no. 1, 1917), p. 6. N.R.E.Fisher, HYBRIS. A Study in the Values of Honor and Shame in Ancient Greece (Aris \& Phillips 1992), p. 419. G.M.A.Grube, The Drama of Euripides (London, Methuen \& Co. Ltd., Gloucester Mass. 1973), 232 n.1.

For the State's three classes according to Aristotle, cf. Pol.1295b.1-3:

$$
\square v \gamma \pi \leq \sigma \alpha \imath \varphi \delta-\tau \alpha \square \varphi \pi \AA \lambda \varepsilon \sigma \imath v \square \sigma \tau \imath
$$

$\tau \rho \square \alpha \mu \square \rho \eta \tau \mathfrak{I} \varphi \pi 囚 \lambda \varepsilon \omega \varphi, o \square \mu \square v \varepsilon \Leftarrow \pi \circ \rho o \imath \sigma \phi \circledast \delta \rho \alpha, o \square \delta \square \infty \pi \circ \rho o \imath$

$\sigma \phi \AA \delta \rho \alpha, o \square \delta \square \tau \rho \square \tau o \imath \quad o \square \mu \square \sigma o \imath \tau o v \tau \omega v$.

See T.H.Irwin, Aristotle's First Principles (Oxford Clarendon Press 1988), pp. 460-461.

${ }^{35}$ Michelini ("Political Themes in Euripides' Suppliants", p. 225) comments that in Theseus' formulation, the two major classes, rich and poor, display the same hubristic greed as the young. There is a saving grace only in the middle group, whose quiet and obedient stance. 


\section{Farid El-ANWAR}

For motives and objectives of the Middle-Class generally, see F.Vannier,

"Euripide; La classe moyenne introuvable", (LEC 52 1984), pp. 99, 102.

${ }^{36} \mathrm{Cf}$. the good rivalry " $\gamma \alpha \theta-\delta^{\prime} \square E \rho \imath \varphi$ " in Hesiod $W \& D 21-24$ :

$\varepsilon \square \varphi \square \tau \varepsilon \rho o v \gamma \leq \rho \tau \square \varphi \tau \varepsilon \square \delta \varepsilon v \square \rho \gamma o \imath o \chi \alpha \tau \square \zeta \omega v$

$\pi \lambda o v \sigma i o v, \sqrt{\varphi} \sigma \pi \varepsilon v \delta \varepsilon \imath \mu \square v{ }^{\prime} \rho \AA \mu \varepsilon v \alpha \imath \equiv \delta \square \phi v \tau \varepsilon v \varepsilon \imath v$

$o \square \kappa \AA \nu \tau^{\prime} \varepsilon \otimes \theta \square \sigma \theta \alpha \cdot \cdot \zeta \eta \lambda o \square \delta \square \tau \varepsilon \gamma \varepsilon \square \tau o v \alpha \gamma \varepsilon \square \tau \omega v$

$\varepsilon \square \varphi \propto \phi \varepsilon v o \varphi \sigma \pi \varepsilon v \delta o v \tau^{\prime} \cdot{ }^{\prime} \gamma \alpha \theta-\delta^{\prime} \square E \rho \imath \varphi \ldots \delta \varepsilon \beta \rho o \tau o \square \sigma \imath v$.

One who lacks work looks at another, a rich man who strives to plow and plan, and to set his household right and neighbor envies his neighbor as he strives for wealth.

See P.Millett, "Hesiod and his World" (PCPS n.s. 30 1984), p. 94, J.Fontenrose, "Work, Justice and Hesiod's Five Ages" (CPh 69 no.1 1974), pp. 12, P.Walcot, Envy and the Greeks. A Study of Human Behaviour (Aris and Philips 1973), pp. 8ff., 102. D.H.Abel, "Genealogies of Ethical Concepts from Hesiod to Bacchylides" (TAPhA 74 1943), p. 93.

${ }^{37}$ See C.Collard, "Euripides, Supplices 176-83", (RIFC 1011973 411-413). A.Michelini, "The Maze of the Logos: Euripides, Suppliants 163-249", (Ramus 201991 ), pp. 17-19. Burian, "Logos and Pathos: The Politics of Suppliant Women", p. 132. McDonald, Terms for Happiness Euripides, p. 101.

${ }^{38}$ See M.C.Fera, "Euripides' Supplici 176-179 e il motive della $\mu \varepsilon \tau \alpha \beta o \lambda \approx \tau \vee \chi \eta \varphi "$ (GIF 38 1986), pp. 255-257. Gamble, "Euripides' Suppliant Women", p. 388.

${ }^{39}$ For Theseus' declaration in the line 236, Michelini ("Political Themes in Euripides' Suppliants", p. 233) explains that the phrase recalls the young Argives whom Theseus accused of seeking $\kappa \square \rho \delta o \varphi$ through support of bellicose policies: this motivation is shared by elite and popular leaders as well.

See also A.E.Haigh, The Tragic Drama of The Greeks (Dover Publications, Inc., New York 1968), p. 276.

For the truth that Euripides often attacks the bad gain, cf. fr. 695.7-8:

$o \square \delta^{\prime} \alpha \square \sigma \chi \rho f \kappa \square \rho \delta \eta \pi \rho R \sigma \theta \varepsilon \tau o \diamond \kappa \alpha \lambda o \diamond \beta \rho o \tau\langle v \zeta \eta \tau o \downarrow \sigma \imath v$.

And for demagogues, see J.Norwood, "Euripides and Demagogues", ( $C Q$ n.s. 59 no. 22009 353-363).

${ }^{40}$ Sheppard ( $T \vee \rho \alpha v v o \varphi, K \square \rho \delta o \varphi$, and the Modest Measure in Three Plays of Euripides, p. 5) supports that the first scene between Theseus and Adrastos is designed to give a new treatment to the motif $K \square \rho \delta o \varphi$, making it nothing less than an indictment of profit-seeking war.

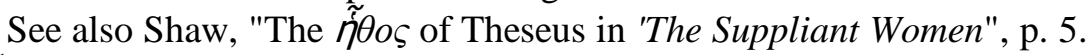

${ }^{41}$ Starkie (Euripides the Politician, p. 200) suggests that the voice is the voice of Theseus, but the thought is that of the 5th century B.C. And L. H. G. Greenwood 


\section{The Concept of Terms Related to Democracy in Euripides' Suppliant Women}

(Aspects of Euripidean Tragedy. Cambridge 1953, p. 112) believes that the criticism of Argos in the whole of the passage (232-245) is meant to apply to contemporary Athenian democracy. And R. Goosens ("Pericles et Thesee,", Bull. de l'Assoc. Guill. Bude, 1932, pp. $17 \mathrm{ff}$.) supports that Theseus' criticisms of Adrastus' rash attack on Thebes echoes Pericles' cautious disapproval of Tolmides' subsequently disastrous expedition.

See also Conacher, "Rhetoric in Euripidean Drama", p. 24.

Cf. Plut. Per. 18.2-3. Hdt. 30.82, where in the Herodotean debate on constitutions, both democracy and oligarchy follow a similar path to destruction, both driven by the greed of their ruling faction and both ending in monarchytyranny.

See Michelini, "Political Themes in Euripides' Suppliants", 225.

${ }^{42}$ See Fisher, HYBRIS. A Study in the Values of Honor and Shame, pp. 419-420.

${ }^{43} \mathrm{Cf}$. Solon fr. 11, 6-7 West: $\sigma v \mu \pi \alpha \sigma \iota v \delta^{\prime} \neg \mu \square v \chi \alpha \diamond v o \varphi \square v \varepsilon \sigma \tau \iota v \ll o \varphi$.

$\square \varphi \gamma f \rho \gamma \lambda(\sigma \sigma \alpha v \angle \rho \vee \tau \varepsilon \kappa \alpha \square \varepsilon \square \varphi \square \pi \eta \alpha \square \mu v \lambda o v$ ' $v \delta \rho \circledast \varphi$,

fr. 34. 4: $\chi \alpha \diamond v \alpha \mu \square v \tau \mathbb{R} \tau^{\prime} \square \phi \rho \leq \sigma \alpha v \tau o$,

Eur. Or.903-906: ' $v \approx \rho \tau \imath \varphi{ }^{\prime} \theta v \rho ® \gamma \lambda \omega \sigma \sigma o \varphi \ldots . .$.

$\theta o \rho v \beta \omega \imath \tau \varepsilon \pi \square \sigma v v o \varphi \kappa^{\prime} \mu \alpha \theta \varepsilon \square \pi \alpha \rho \rho \eta \sigma \square \alpha l, \pi \imath \theta \alpha v \Pi \varphi$

${ }^{44}$ For the private gain as a political motive in democracy, cf. Thuc. 2.65.7.6-8: $\infty \lambda \lambda \alpha \square \xi \omega \tau o \downarrow \pi \circ \lambda \square \mu o v \delta o \kappa o \downarrow v \tau \alpha \varepsilon \square v \alpha \imath \kappa \alpha \tau f \tau f \varphi \square \delta \square \alpha \varphi$ $\phi \imath \lambda o \tau \imath \mu \square \alpha \varphi \kappa \alpha \square \square \delta \imath \alpha \kappa \square \rho \delta \eta \kappa \alpha \kappa l \varphi \square \varphi \tau \varepsilon \sigma \phi \varphi \varphi \alpha \wedge \tau o \Uparrow \varphi \kappa \alpha \square$ $\tau o \Uparrow \varphi \xi v \mu \mu \leq \chi \circ v \varphi \square \pi \sigma \lambda \square \tau \varepsilon v \sigma \alpha \nu$,

See J.H.Finley, "Euripides and Thucydides", (HSPh 49 1938), pp. 42, 44, 59.

${ }^{45}$ For the demagogues' slanders, cf. Thuc. 5. 16. 1. 4-6:

$\angle \delta \square \gamma \varepsilon v o \mu \square v \eta \varphi \neq \sigma v \chi \square \alpha \varphi \kappa \alpha \tau \alpha \phi \alpha v \square \sigma \tau \varepsilon \rho o \varphi v o \mu \square \zeta \omega v \vee v \varepsilon \square v \alpha \imath \kappa \alpha \kappa o v \rho$ $\gamma / v \quad \kappa \alpha \square ' \pi \imath \sigma \tau \ll \tau \varepsilon \rho o \varphi \delta i \alpha \beta \leq \lambda \lambda \omega v$,

${ }^{46}$ See Burian, "Logos and Pathos: The Politics of Suppliant Women", p. 141. Shaw, "The $\tilde{\eta} \theta$ o of Theseus in 'The Suppliant Women", p. 4.

${ }^{47}$ See Michelini ("Political Themes in Euripides' Suppliants", p. 233.

${ }^{48} \mathrm{Cf}$. Xen. Hist. Ath. Resp. 1.6-7, 11, where the inferior people, as the "Old Oligarch" points out, may choose leaders who are like them, with disastrous results for civic unity and rational policy.

See Michelini, "Political Themes in Euripides' Suppliants", 234.

${ }^{49}$ See Hook, "The Praise of Athens in Greek Tragedy", p. 187.

${ }^{50}$ Gamble (Euripides' Suppliant Women, p. 397) explains that the glory or excitement of war is easily seen, but men do not consider the possibility of death. As the mothers' view of the return of the dead was one-sided, so too do men take a similarly limited view of going to war. In both cases, human ignorance and 


\section{Farid El-ANWAR}

inability to see, before the event (482), the opposite tendencies of the action has a result in pain and suffering.

Cf. Suppl. 734ff., where Adrastos describes how his expedition against Thebes went against what seemed to be the probabilities.

${ }^{51}$ For the concept of war in this play, J. W. Fitton ("The Suppliant Women and the Herakleidai of Euripides: I. The Suppliant Women", Hermes 89 no. 41961 p. 433-434) suggest that the particular point that war is the enemy of culture, we may be sure, was an authentic Euripidean sentiment'. The trenchant lines on the fatal facility with which an Assembly votes for war (484-5) remind us of the ease with which Theseus obtained the support of the Demos, and no doubt had plenty of point for the Athenian audience. Euripides combines culture with the material blessings of peace.

Cf. Eur. fr.369 N.2 (Erechtheus): "the spear and shield must yield to the garlands of poetry"; Eur. fr. 453 N.2 (Kresphontes): "Peace is here at last, with beautiful choirs and garlanded bands".

${ }^{52}$ See Gamble, "Euripides' Suppliant Women", p. 398.

${ }^{53}$ See Burian, "Logos and Pathos: The Politics of Suppliant Women", p. 144. McDonald, Terms for Happiness Euripides, pp. 105-106.

${ }^{54}$ For the speech of Adrastos, Shaw (The $\tilde{\eta} \theta$ os of Theseus in 'The Suppliant Women, p. 11) comments that Adrastos' sentential true, but we must add that it is true for those cities who have not chosen a leader like Theseus. Adrastos' city, however, has chosen him, and they must suffer the destiny which this choice entails. See also Michelini, "Political Themes in Euripides' Suppliants", 240. Smith, "Expressive Form in Euripides' Suppliants", HSCPh 71 (1967) p. 161.

${ }^{55}$ See Fisher, HYBRIS. A Study in the Values of Honor and Shame, p. 419-421.

\section{Bibliography}

\section{Sources}

Collard C., ed., Euripides Supplices, 2 Vols. (Groningen 1975).

Diggle J., ed., Euipides Fabulae, 3 Vols. (Oxford University Press (19811994).

Hude C., ed., Herodoti Historiae,Vol. I (London Oxford University Press 1972).

Jones H.S., ed. Thucydidis Historiae (Oxford University Press 1970). 


\section{The Concept of Terms Related to Democracy in Euripides' Suppliant Women}

Murray G., ed. Euipides Fabulae, 3 Vols., Oxford Classical Texts (London Oxford University Press 1978).

Nauck A. Tragicorum Graecorum Fragmenta, Vols. 3,4 (Vandenhoeck \& Ruprecht in Gottingen 1985).

Pearson A.C., ed. Sophocles Fabulae.(Oxford University Press 1975).

Rzach A., Hesiodi Carmina (Lipsiae, in Aedibus B.G. Teubneri MCMII).

Thesaurus Linguae Graecae (TLG-E), (University of California, Irvine 2000).

West M.L., Delectus ex Iambis et Elegis Graecis (London, Oxford University Press 1980).

, Hesiod: Works and Days (London, Oxford University Press 1978).

\section{Studies}

Adkins A.W.H., Moral Values and Political Behavior in Ancient Greece from Homer to the end of the Fifth Century (London 1972).

Burian P., "Logos and Pathos: The Politics of Suppliant Women": Directions in Euripidean Criticism. A Collection of Essays (Duke University Press, Durham 1985), 129-155.

Collard C., "Euripides, Supplices 176-83", (RIFC 101 (1973) 411-413).

Conacher D. J., "Rhetoric and Relevance in Euripidean Drama" AJPh 102 no. 1 (1981) 3-25).

, "Religious and Ethical Attitudes in Euripides' Suppliants", (TAPA 87 (1956) 8-26).

Finley J.H., "Euripides and Thucydides", (HSPh 49 (1938) 23-68).

Fisher N.R.E., HYBRIS. A Study in the Values of Honor and Shame in Ancient Greece (Aris \& Phillips 1992).

Fitton J. W., "The Suppliant Women and the Herakleidai of Euripides: I. The Suppliant Women", (Hermes 89 no. 4 (1961) 430-461). 


\section{Farid El-ANWAR}

Gamble R. B., "Euripides' Suppliant Women: Decision and Ambivalence", (Hermes 98 no. 4 (1970) 385-405).

Greenwood L. H. G., Aspects of Euripidean Tragedy (Cambridge 1953).

Goosens R., "Pericles et Thesee", Bull. de l'Assoc. Guill. Bude (Avril 1932) 9-40).

Haigh A.E., The Tragic Drama of The Greeks (Dover, New York 1968).

Hook L.V., "The Praise of Athens in Greek Tragedy", ( $C W 27$ no. 24 (1934) 185-188).

MacDowell D.M., "Hybris in Athens", (G\&R n.s. 23 no. 1 (1976) 14-31).

McDonald M., Terms for Happiness Euripides (Hypomnemata 54. Gottingen 1978).

Michelini A.N., "Political Themes in Euripides' Suppliants", ( AJPh 115 no. 2 (1994) 219-252).

, "The Maze of the Logos: Euripides, Suppliants 163-249", (Ramus 201991 ) 16-36).

Norwood J., "Euripides and Demagogues", ( $C Q$ n.s. 59 no. 2 (2009) 353$363)$.

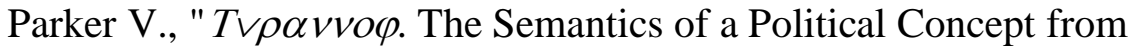
Archilochus to Aristotle", (Hermes 126 (1998) 145-172).

Raaflaub K.A., "Contemporary Perceptions of democracy in Fifth Century Athens", ( $C \& M 40$ (1989), 33-70).

" Democracy, Oligarchy, and the Concept of the "Free Citizen" in Late Fifth-Century Athens", (Political Theory vol. 11 no. 4 (1983), 517-544).

Rhodes P. J., "Nothing to Do with Democracy: Athenian Drama and the Polis", (JHS 123 (2003) 104-119).

Roselli D.K., "Gender, Class and Ideology: The Social Function of Virgin Sacrifice in Euripides' Children of Herakles", ( $\mathrm{Cl}$ Ant 26 no. 1 (2007) 81-169). 


\section{The Concept of Terms Related to Democracy in Euripides' Suppliant Women}

Rosenbloom D., "From Ponêros to Pharmakos: Theater, Social Drama, and Revolution in Athens, 428-404 BC", (Cl Ant 21 no. 2 (2002) 283346).

Rosivach V.J., "The Tyrant in Athenian Democracy", (Quaderni Urbinati di Cultura Classica n.s. 30 no. 3 (1988) 43-57).

Sarachek B., "Greek Concepts of Leadership", (AMJ 11 no. 1 (1968) 3948).

Shaw M.H., "The $\Re \theta o \varphi$ of Theseus in 'The Suppliant Women", Hermes 110 (1982) 3-19).

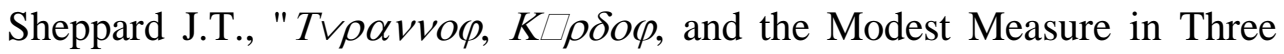
Plays of Euripides", (CQ 11 no. 1 (1917) 3-10).

Smith W.D., "Expressive Form in Euripides' Suppliants", (HSCPh 71 (1967) 151-170).

Starkie W. J. M., "Euripides the Politician", ( $Q R 9$ no. 34 (1920) 195-212).

Thury E.M., "A Study of Words Relating to Youth and Old Age in the Plays of Euripides and Its Special Implications Euripides' "Suppliant Women", (Computers and the Humanities 22 no. 4 (1988), 293306).

Toher M., "Euripides' Supplices and the Social Function of Funeral Ritual", (Hermes 129 (2001) 332-343).

Yialoucas C.S., The Conflict of $\Delta \otimes \xi \alpha$ and $A \lambda \approx \theta \varepsilon i \alpha$ in Euripides and Predecessors (Ph.D. University of California 1981).

www.jstor.org.

www. eulc.edu.eg.

www. sciencedirect.com.

www.proquest.com.

www.goodreads.com.

www.4share.com.

www.textarchive.com. 